\title{
Organizational Communication Responses to Covid-19: Strategies and Practices
}

\author{
https://doi.org/10.25008/jkiski.v5i2.419 \\ Dorien Kartikawangi ${ }^{1 *}$, Rayini Dahesihsari ${ }^{2}$ \\ ${ }^{1}$ School of Communication, Faculty of Business Administration and Communication Science \\ Atma Jaya Catholic University of Indonesia \\ ${ }^{2}$ Faculty of Psychology, Atma Jaya Catholic University of Indonesia \\ Jl. Jenderal Sudirman Kav. 51, Jakarta 12930 - Indonesia \\ ${ }^{*}$ Corresponding author: dorien.kartika@atmajaya.ac.id
}

Submitted: November 01, 2020, Revised: November 23, 2020, Accepted: December 18, 2020

Accredited by Kemristekdikti No. 28/E/KPT/2019

\begin{abstract}
In a crisis situation, employees are facing pressures and challenges because they have to deal with unexpected disruption in their routine working conditions with high level of uncertainty. Organizational communication strategies and practices play important roles in giving employees information, direction and support. This research aims to explore how are the responses of organizational communication strategies and practices to such a specific crisis: Covid-19 Pandemic, using situational crisis communication theoretical framework. This research applies qualitative approach. This research involves four organizations, two business organizations and two educational organizations which were selected using maximum variation sampling technique. Four people representing each of the organizations were interviewed using inductive method. Data was analyzed using thematic analysis. The findings show that organizational communication strategies and practices being used by all participants' organizations are mostly related to the preparation stage and the response stage of the crisis management. Early crisis management planning, forming crisis management teams and preparing supporting communication system, including providing health care facilities and communication protocols for infected employees are salient practices during the preparation stage. In the response stage, leader and horizontal communication intensively used a variety of media and channels. Interestingly, informal communication was minimized, while formal communication was conducted intensively and transparently. Furthermore, sensitivity to employees' needs and conditions as well as emphatic communication expressing positive emotion and support was perceived as positive to help employees understand the information well and to feel understood and appreciated.
\end{abstract}

Keywords: crisis management; organizational communication; pandemic Covid-19; situational crisis; communication theory

\section{Introduction}

Since the onset of corona virus pandemic which leads to global crisis, some of business entities and their leader are facing challenges to self-acceleration toward the sudden and rapid change that shows direction to new reality and defends their businesses. A new strain of novel coronavirus was first detected in Wuhan of 
China in December 2019. Actually, the coronavirus outbreak in Wuhan has been announced widely and the Government of China imposed a lockdown policy in Wuhan City. Aware of the outbreak other countries including Indonesia took precautionary measures to avert the spread of the coronavirus.

However, media news about the epidemic has yet to be responded by the government and public even though some business sectors, particularly the tourism industry in China has received its impact. In response, other countries started to close their entry points. A spike in the number of cases has been recorded in Indonesia since President Joko Widodo announced the country's first confirmed case on March 2, 2020, which results in the crisis as if the organisations had been suddenly attacked.

Based on the observation and discussion with business entities in Indonesia the crisis situation was felt by the management. It is stated that Jakarta emerged as the epicentre of the coronavirus in Indonesia, which gradually influenced businesses outside the capital and Java island. Within a period of 45 days after the announcement by the President, the crisis spread rapidly to several sectors of business without exception.

Under these circumstances, all points of business chains worldwide suffer the impact. The multiple domino effects prompted the management of business entities to make decision in due course. Some of them decided to close and declare bankruptcy due to financial difficulties. Some of them curtailed and curbed their operating costs to survive.

Meanwhile, employees face challenges and pressures because of unpredictable disruption in their routine work, uncertainty about its impact on work safety and uncertainty about health and safety problem. During the complicated and uncertain situation, the employee will refer to top leader for gaining information, directions, guarantee and support. Within a crisis situation, the leader plays its role as the main communicator (Coombs, 2010; Men \& Stacks, 2014).

Where the Covid-19 is concerned, the leader is expected not only to provide clear and trustful information to enable employees to understand the situation, but also to support them in facing the crisis which is emotionally so disturbing. The role and involvement of the leader in such situation can create employees' satisfaction and productivity. Support from the organization and supervisor perceived by employees through communication has a significant impact on employee engagement (Albrecht, 2012; Joo \& Lee, 2017; Krishnan, 2013).

Employee engagement refers to employees' positive thought about their jobs indicated by vigor, dedication and absorption (Schaufeli, Bakker, \& Salanova, 2006). In this context, formal and informal information gather in many available communication media with its capability to spread out rapid information. Welch \& Jackson ( 2007) proposes an Internal Communication Matrix which could be used to supplement other forms of internal situational analysis and as an analytical tool which may be applied to the strategic analysis, planning and evaluation of internal communication. While Men and Yue (2019) suggest that symmetrical communication and responsive leadership communication cultivated a positive emotional culture in organizations.

Crisis management visualizes some factors that are designed to overcome crisis and to reduce damages because of its presence. In the other words, the crisis management to prevent or to reduce negative impact of crisis and therefore to protect organisation, stakeholders and company against disaster. Crisis management develops from the involved emergency readiness those are prevention, readiness, response and revision (Coombs, 2004, 2007a; Jaques, 2007). Prevention, known as mitigation or handling, is a set of steps taken to avoid crisis.

Readiness is the most famous factor in crisis management because it includes crisis management plan - CMP. Readiness also includes diagnostic of crisis vulnerability, conducts selection and training of crisis management team and its spokesman, and creates crisis portfolio and updates crisis communication system. Response is an application of readiness components toward crisis. A part of response is recovery which means an effort intended to company to reoperate normally as soon as possible after the crisis is over. Revision includes evaluation of organization-response toward crisis, determining whether the implementation of crisis handling protocol is true or false.

At present, the macro environment seems 
to support crisis management to become an important thing that needs special attention because creating some kind of business is vulnerable to crisis. With the improving awareness of the importance of reputation, communication plays a central role in the process of crisis management (Kartikawangi, 2014; Nugroho, F. A.; Kartikawangi, 2016; Tongam, Hans C.D.; Kartikawangi, 2018).

In business practices, communication is adhesive among all parts and intra parts within system unity, and between systems with suprasystem. Besides its role in management and coordination, communication also plays a role as a canal of participation in decision making; accelerating subsystem with the whole system as well as accelerator of organisation toward environment.

Based on decision-making literature, Claeys \& Coombs (2020) argue that the distinct context in which crisis communication takes place determines whether or not decisions are made in an analytical or intuitive manner. In the context of crisis, all kinds of communication are used in accordance with their needs and effectivity. Such situation needs sensitiveness toward content, situation and communication context.

How about direction of communication? In a crisis situation, business needs communication to all directions within the system, i.e vertically downward, upward, horizontally and diagonally and to all steps over the environment boundaries.

In digital era, communication map in the crisis as mentioned in advance is facilitated by communication canal such as WhatsApps, line, mesanger and others. Digital communication canals provided by group facility with members that consists of several managerial function causing the communication occurence (Gonzalez-herrero, 2010). Such digital communication is very efficient eventhough its effectivity must be provided.

Why? Digital communication brings consequency to treat of overload canals, chaos, and scaterred communication due to time limit. It also creates possibility of wider distortion like message-delete, insensitivy toward negative feedback, frustation, neglation and isolation. Within crisis sitation, a formal communication owns a higher credibility to be trusted (Gossieaux \& Moran, 2010).

However, the informal communication is least important. Based on the background described, this research is intended to explore how an organisation communication is conducted to respond to a specific crisis, in this case the Covid-19 pandemic.

\section{Theoretical Framework}

Marsen, (2020) overviews some major theories of crisis communication and their different methodologies: image repair, situational crisis communication theory, rhetorical arena theory, narrative, and integrated crisis mapping. It ends with a description of some lessons learned that apply to all approaches and an overview of the contributions to the issue. In this context, the author implements Situational Crisis Communication Theory (SCCT) as the basic theory which was initiated by W. Timothy Coombs, as a combination of attribution theory.

SCCT has three basic elements i.e crisis situation, communication system accelerated with crisis situation and appropriate crisis handling strategy. It means that in general, a company or organization shall recognize the crisis situation first and then determine action to face crisis via communication by implementing appropriate crisis handling strategy. SCCT is applied to describe reaction from internal and external toward crisis situation and reputation occurring in a company and organization. SCCT describes communication that influences anybody or group in understanding any crisis. Here means that the words used and the action taken by crisis management are capable of influencing people to understand organization or crisis. SCCT is focused on how a company can anticipate crisis and prevent it from reputation devastation (Coombs, 2007b).

Figure 1 visualizes how response to crisis is evaluated. This model is provided to give understanding about SCCT, even though this research does not reach evaluation step yet. This is because the research was conducted when the organization faced a crisis caused by the impact of the Covid-19 pandemic. With this in mind, the research exploration focuses on the step of preparation and response. 


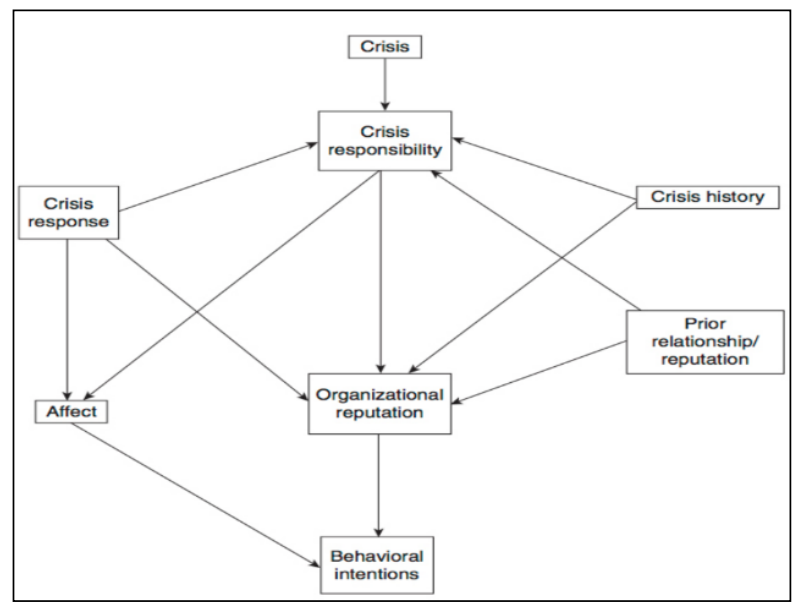

Figure 1. An Evaluation Model of Crisis Response

Source: Coomb, 2007

Coombs, (2007b) believes that company reputation depends on how public can accept company response to crisis. An appropriate crisis response will be able to turn-back legitimation and guarding company reputation even, it is capable to improve the company financial (Coombs, 2010). Coombs provided ten crisis-response strategies capable of assisting crisis manager in protecting reputation asset and making preparations for crisis mitigation. Table 1 shows a group of ten response strategies that can be used as a cluster analysis study.

Table 1. Crisis response strategies in the SCCT cluster analysis study

\begin{tabular}{|c|l|l|}
\hline 1 & Denial & Management claims there is no crisis \\
\hline 2 & Scapegoat & Management blames some outside entity for the crisis \\
\hline 3 & Attack the Accuser & $\begin{array}{l}\text { Management confronts the group or person claiming that something } \\
\text { is wrong }\end{array}$ \\
\hline 4 & Excuse & $\begin{array}{l}\text { Management attempts to minimize crisis responsibility by claiming } \\
\text { lack of control over the event or lack of intent to do harm }\end{array}$ \\
\hline 5 & Justification & $\begin{array}{l}\text { Management attempts to minimize the perceived damage caused by } \\
\text { the crisis }\end{array}$ \\
\hline 6 & Ingratiation & $\begin{array}{l}\text { Management praises other stakeholders and/or reminds people of } \\
\text { past good works by the organization }\end{array}$ \\
\hline 7 & Concern & Management expresses concern for victims \\
\hline 8 & Compassion & Management offers money or other gifts to victims \\
\hline 9 & Regret & Management indicates they feel badly about the crisis \\
\hline 10 & Apology & $\begin{array}{l}\text { Management accepts full responsibility for the crisis and asks } \\
\text { stakeholders for forgiveness }\end{array}$ \\
\hline
\end{tabular}

Source: Coombs, 2009

\section{Material and Methodology}

This research applies qualitative approach to enable exploring deep strategy, practices and communication process that happen in organization during the crisis, particularly the Covid-19 pandemic. Four organizations are selected as participants in this research by considering a variety of industrial types and organization size. Two of the participants are business organizations, while the other two are educational institutions.

One of the business organizations is a large scale, or multinational corporation, while the other one is a medium scale. One of the educational institutions has complete educational levels, ranging from elementary to higher education, while the other one is a smallscale educational institution for students with special needs. The variety of industrial types and organization sizes are supposed to represent present organizations. Sampling technique used is maximum variation sampling-technique (Creswell, 2014).

Data is gathered by conducting interviews with key resource persons at each of the organizations. Interview-guidance is made 
based on inductive approach. The questions raised to resource persons is designed for general and open concerning how strategy and communication practices are applied within organization during the Covid-19 pandemic, which are then to be explored deeply in detail (Creswell, 2014). The interviews were conducted from 13 to 29 April 2020. The interviews lasted for 90 minutes for each resource person of each of the organizations. All interviews are recorded as audio under the agreement with the resource persons.

The entire recordings were then transmitted into written documents by assigning a code to each of them using theoretical frame of situational crisis communication (Coombs, 2006). The two researchers conducted coding and analysis separately to ensure inter rater data validity. The final form of such coding is then to be compared and discussed to reach an agreement on the relevant theme of data observed.

Thematic descriptive analysis was used to analyze the meaningful theme (Berg, B. L., 2017). Summary of such theme is provided in the following sub-paragraphs accompanied by direct citation of interview by anonymizing resource person.

\section{Result and Discussion}

The results of this research will describe relevant themes which are analyzed using theoretical frame of situational crisis communication (Coombs \& Holladay, 2009). The relevant themes, as mentioned in the results of this research, are stated in the context of effort to crisis management as forwarded by Coombs (2004, 2007) and Jaques (2007) intended to protect organization and all stakeholders of organization against disaster by preventing or decreasing the negative impact of crisis. Referring to the steps of crisis management, in general, strategy and organization communication practices conducted by the whole organization involved in this research were positioned in the step of preparation and response.

In the preparation step, there are several matters done by the organization among others as follows. Crisis management plan; within organization is to anticipate crisis situation before the presence of government regulation and policy. An anticipative policy as output of directive meeting is then to be communicated step by step to the employees. Therefore, there is no huge amount of stagnant information to employees because such sudden and direct information is considered to create confusion, unclearness and even panic.

"After identifying the case and awaiting government policy for PSBB known as Largescale Social Restrictions, the top management already prepare policy for work from home, to make sure support of IT, to anticipate some countries commencing lock down. There are grouping policy based on job description of employee to have a shift-work aiming to reduce employee working at the office in the framework of social distancing for middle-scale Company".

\section{To Establish Team or Committee for Crisis Management \\ The other matter done during preparation} step is the organization's effort to establish a team for crisis management. Both participants of business organization implement this matter.

"We establish team for crisis management by recruiting member representative of each division. They are ordered to seek information on Covid-19 and to inform it to all division to provide reliable and accurate information can be provided via WhatsApp group, email and Instagram. The objective is to provide as much as possible accurate information from formal source with the aim of avoiding employee from unreliable and hoax information of outside source". This is done by the middle scale company.

\section{To Build-Up Supporting Organization Communication System}

Other thing happen in preparation step is to prepare portfolio and to renew crisis communication system. Within all organization participants, a sum of guidance and working-procedures are prepared for directing and describing members particularly to support the change of working procedure.

"Availability of communication protocol and social media usage. Working protocol, for example from 12:00 to 13:00 stop working and finish at 16:00; therefore remain clarity of working hour even though work from home" (Multinational company).

"Always available information update regularly and intensively on what is going on, but in a limited size and easy to understand (bite size and snackable content). Day by day is updated, provided in a daily video, to guarantee 
the availability of updated recent development" (Multinational Corporation).

"Every day is warned to check their health at home" (Middle Scale Company).

"FAQ is provided to allow surrounding questions" (Multinational Corporation).

"To enhance internal communication to enable all talent to adapt" (Middle Scale Company).

\section{Provision of Health Facility}

In general, during crisis situation, the employees face pressure on their health and security. Therefore, beside information on prevention and protection in the face of Covid19 the provision of ample health-facility to keep employees informed intensively shows the seriousness of management to protect them and build-up their awareness.

"Provision of hand sanitizer, body temperature measurement" (school for student with special needs).

"Provision of multivitamin for all members" (university).

\section{Communication Protocol for Employees Infected with Covid-19 \\ Information on protocols for infected people is provided to enable employees to get clarity on what to do. This indicates that management is involved in responsibility.}

"When showing symptoms, the employee is requested to fill in the online form and the cost is covered by the company" (middle scale company).

"Employee is ordered to report by email, which is then followed by team for directive actions." (Multinational Corporation).

"Availability of health service poster includes contact person in case of symptoms" (university).

\section{Response Steps}

All the participating organizations conduct strategy and communication practices that are generally done in response step. Some of the strategies are conducted as follows:

\section{Organization Leader as the Main Communicator \\ Theoretical concept on Crisis} Communication states that leader is the main communicator within crisis situation because during such situation all members or employees refer to the leader for gaining information, directive actions, guarantee and support (Coombs, 2010; Men \& Stacks, 2014).

The finding also supports such concept. In all participating organization, the changing policy on working scheme to work from home is delivered by organization leader via formal decision letter and generally provides one-week duration before being fully implemented.

"The Decree of Rector concerns online learning and work from home policy. The policy includes trials of one-week online learning. In case of problem, it will be resolved before the policy is fully implemented" (university).

"Meeting and circular letter from the Principal distributed via email and WhatsApp" (school for students with special needs).

\section{Intensive Crisis Communication using All Available Channels and Media}

Beside information related to a change in the scheme of work from home, the organization also provides intensive information on crisis related to Covid-19 to improve all employees' awareness. Information is also provided at workplaces to employees to work at office due to the nature of jobs that cannot be done from home. Media used varies, including banner, poster, digital media such as web site, email, WhatsApp group and Instagram and direct education by teacher or lecturer in educational institution (Jacob, 2020).

"There is banner on how to keep clean, wash hands and use face masks," (Middle Scale Company).

"Within Instagram, there is poster on symptoms, prevention, and appeal not to go to his home-village includes the possible risk. Similar information for factory is provided via several banners (Middle Scale Company).

"Lecturer is requested to teach university students about Covid-19, socialization on early prevention of Covid-19, understanding of social distancing for online learning" (university).

"Teacher makes poster and education video for students about Covid-19" (school for student with special needs).

"Snackable and sharable information about Covid 19, formats across channels". (Multinational Corporation). 
Acceleration in the Way and Media Communication Used

Despite using several channels and media intensively, the way of disseminating information needs to be accelerated based on the target audiences, including type of information to be delivered so that information can be accepted effectively.

"Banners at the factory and at the office and Instagram might have the same messages but the use of different languages and packaging must be considered in accordance with the target audiences" (Middle Scale Company).

"Different tones of voices, for a serious matter, more formal language" (Multinational Corporation).

\section{Sensitivity toward the Needs, Employee} Condition and Emphatic Communication

Besides forwarding information clearly and accurately, communication in crisis situation particularly conducted by the organization leader shall function to support emotional condition to employees. Before the large scale social restriction (PSBB) policy was imposed, organization had already asked employees who were at high risk of contracting the Covid-19 to start work from home. The policy was intended to respond to the needs and condition of organization members who were at high risk of contracting the Covid-19 feel understood and protected by the management.

"Furthermore, the work from home policy applies to employees aged 40 years or over, who go to the office by public transport modes, and have family members who work in the place infected by Covid-19. The policy took effect before the PSBB was imposed by the provincial government. The employees agree to and laud the company's policy" (Middle Scale Company).

Besides, the way of forwarding information that touches emotional side persuasively is considered effective. The impact of such way is that the information is understood more easily and the employees feel more respected and noticed.

"Appeal not to go to home-village forwarded via video touching empathy of employees longing for their family, but to postpone going to their home-village will be valuable for their family. An impressive picture and message for employees is viewed as an effective way. Message involving emotion will be more persuasive way" (Multinational Corporation).

"Message for factory employees that must work at the office highly touches them. During the Covid-19 pandemic, most people are requested to stay at home, but some of us must struggle to go outdoors. They do so not to challenge it but rather they have no more choice. No more choice because the work is impossible to be done at home. No more choice because part of us is the front-garda to maintain company productivity and guarding sustainability of work-place and gaining income for family" (Middle Scale Company).

\section{Horizontal Communication or Peer Communication}

In line with crisis communication concept forwarded by (Coombs, 2010) it is stated that communication within crisis situation occurs in all directions, even though leader is the main communicator. In all organization participants, information doesn't come directly from management but it involves among employee, too. An active participation among employee in the information dissemination is considered more effective, wider and more persuasive. Besides, communication among employee can assist them to overcome handicap in accelerating the change of working-demand by sharing experience and learning together.

"Appeal doesn't come only from management but also come among employee. In Instagram employee can post his picture wearing masker. This matter increase discipline of masker usage for employee" (Multinational Corporation).

"While teacher facing difficulty to develop an attractive teaching material for home learning, meeting among teachers to discuss material preparation can help teacher not to feel alone in taking new responsibility, includes learning new skills" (school for student with special needs).

"Sharing spirit each other, let us share our roles, the way is obvious" (Middle Scale Company).

Horizontal communication also functioning to assist distribution of appropriate human resources needed by working division.

"During pandemic Covid-19, any part of organization gets minimum work meanwhile other part is more busy than before, it is assisted by application to be communicated which part 
of project needs more human resources. All employee is permitted to request assistance" (Multinational Corporation).

\section{Informal Communication}

In all organization participants, the formal communication seem more dominant used during crisis situation of pandemic Covid19. Communication protocol is prepared seriously to assist employee in gaining information, direction and support. Organization makes an effort to minimize informal communication during crisis situation with the aim for employee to gain accurate information from reliable source that can be fully handled.

"If the transparency is strong, informal communication will be minimum" (Multinational Corporation).

"There are a lot of less-accurate information to be shared informally that leads to panic and rowdy, that is the task of management crisis team to provide reliable information for employee" (Middle scale company).

\section{To Build-Up Reputation via External Communication}

It needs to prepare communication protocol with the external organization to maintain relation with external organization and the activities conducted together with external organization remain well coordinated. Besides, a sum of social activities conducted by organization shows its contribution for public during such crisis situation.

"Public relation team informs meeting procedures with campus-party and shares activity involving external party facing the changes of scheme and time" (University).

"We conduct social actions involving employee and social movement for gaining funding" Middle Scale Company).

"We conduct fund-gaining and to test specimen for wider public" (University).

Looking at the research finding, the following table 2 provides strategy and organization communication practices that is conducted by the organization to face crisis due to pandemic Covid-19.

Table 2. Strategy and Organization Communications Practices to Face Covid-19 Crisis

\begin{tabular}{|c|c|}
\hline Planning Step & \\
\hline \multirow{4}{*}{ Crisis Management Plan } & $\begin{array}{l}\text { To organize team or committee on crisis } \\
\text { management }\end{array}$ \\
\hline & $\begin{array}{l}\text { To build supporting organization communication } \\
\text { system }\end{array}$ \\
\hline & To provide health facility \\
\hline & $\begin{array}{l}\text { To provide communication protocol for Covid-19 } \\
\text { infected employee }\end{array}$ \\
\hline \multicolumn{2}{|l|}{ Response Step } \\
\hline \multirow[b]{2}{*}{ Justification } & Organization leader as main communicator \\
\hline & $\begin{array}{l}\text { Intensively crisis communication using all available } \\
\text { channels and media }\end{array}$ \\
\hline Ingratiation & $\begin{array}{l}\text { Sensitivity to the needs, employee condition and } \\
\text { emphatic communication }\end{array}$ \\
\hline \multirow{3}{*}{ Concern } & Horizontal or peer communication \\
\hline & Informal communication \\
\hline & To build reputation via external communication \\
\hline
\end{tabular}

Based on the above-mentioned research finding it is known that in the crisis management, organization communication plays a central role in preparation step and response step. Within the case of crisis as the impact of Covid-19 as external factor of organization, the finding shows that internal communication must become main focus. The important role of internal communication is mainly in information distribution and rapid and effective socialization concerning the organization policy to face Covid-19.

Leader as main communicator within formal communication can build employeetrust toward policy made by organization. The clear and easy to take formal communication is very important to reduce information uncertainty and ambiguity.

Within the research, besides leader as the main communicator, the usage of many channel and available media to become practices to 
support information distribution speed. A good internal crisis handling will contribute to internal reputation of organization. Organization members to gain attention via gaining clear information and keeping silent in crisis situation will be able to maintain his performance. A stable internal situation contributes to organization external reputation. The external stake holders to see how an organization handles crisis externally will not lose trust. Thus, organization reputation is guarded and maintained.

\section{Conclusions}

Based on the result of research it can be concluded that whenever crisis attacks the organization is to take a quick response in handling such crisis. The preparation can involve several competent parties which is grouped in the team of crisis management with the ultimate task of planning strategy to overcome the crisis and its practices. For the planning and response, the organization internal-communications plays an important role for formal and informal actions, as well as in information distribution and socialization on how to implement the organization policy to handle crisis.

There are three of the ten Coomb's strategy (Coombs \& Holladay, 2009) implemented to response Covid-19 crisis, i.e justification, ingratiation and concern.

The data used in such research is mainly the result of interview with management. Therefore, it is advised to involve employee for the next research by implementing quantitative approach to enable seeking the whole opinion of the employee. For practical purpose, it can be advised to see the important role of management in the formal communications. Therefore, the management shall be aware of such role for the purpose of conducting good communication, keeping silent by continuing motivation to organization-members with the main aim of sustaining their performance.

\section{Acknowledgement}

The writer herewith forwards gratitude and highly appreciation to Messrs. Ledwin Liantama, Tasya Adelheid, Puspa Triani Adinda, Winda Alamanda, Carolina Dindy Dwi Miranti, Bertha Taga, Julian Adrian Halim, Atikah Fairuz Renggani, Serly Oktavia for their assistance in collecting research data.

\section{References}

Albrecht, S. L. (2012). The influence of job, team and organizational level resources on employee well-being, engagement, commitment and extra-role performance. International Journal of Manpower, 33(7). https://doi.org/10.1108/0143772121126 8357

Berg. B. L. (2017). Research Method for the Social Sciences. Long Beach: Pearson.

Claeys, A.-S., \& Coombs, W. T. (2020). Organizational Crisis Communication: Suboptimal Crisis Response Selection Decisions and Behavioral Economics. Communication Theory, 30(3). https://doi.org/10.1093/ct/qtz002

Coombs, W. T. (2004). Impact of past crises on current crisis communication: Insights from situational crisis communication theory. Journal of Business Communication.

https://doi.org/10.1177/0021943604265 607

Coombs, W. T. (2006). The Protective Powers of Crisis Response Strategies. Journal of Promotion Management, 12(3-4). https://doi.org/10.1300/J057v12n03_13

Coombs, W. T. (2007a). Attribution Theory as a guide for post-crisis communication research. Public Relations Review, 33(2). https://doi.org/10.1016/j.pubrev.2006.11 .016

Coombs, W. T. (2007b). Attribution Theory as a guide for post-crisis communication research. Public Relations Review. https://doi.org/10.1016/j.pubrev.2006.11 .016

Coombs, W. T. (2010). Conceptualizing crisis communication. In Handbook of Risk and Crisis Communication. https://doi.org/10.4324/978020389162911

Coombs, W. T., \& Holladay, S. J. (2009). Further explorations of post-crisis communication: Effects of media and response strategies on perceptions and intentions. Public Relations Review, 35(1).

https://doi.org/10.1016/j.pubrev.2008.09 .011

Creswell, J. W. (2014). Educational research: Planning, conducting, and evaluating quantitative and qualitative research (4th ed). Boston: Pearson education Inc. 
Gonzalez-herrero, A. (2010). Crisis Communications Principles to Manage Crisis in an Online World . 1. Organization Development Journal.

Gossieaux, F., \& Moran, E. K. (2010). The Hyper-Social Organization. New York: McGraw Hill.

Jaques, T. (2007). Issue management and crisis management: An integrated, non-linear, relational construct. Public Relations Review.

https://doi.org/10.1016/j.pubrev.2007.02 .001

Jacob, O. N. (2020). Impact of COVID-19 Pandemic School Close Down on the Research Programme of Higher Institutions. International Journal of Advances in Data and Information Systems, 1(1), 40-49. https://doi.org/10.25008/ijadis.v1i1.189

Joo, B. K., \& Lee, I. (2017). Workplace happiness: work engagement, career satisfaction and subjective wellbeing. Evidence Based HRM: A Global Forum for Empirical Scholarship, 5(2), 216-221.

Kartikawangi, D. (2014). Communication and the triangle of crisis: a case in Indonesia. Retrieved from https://lib.atmajaya.ac.id/default.aspx?ta $\mathrm{bID}=61 \& \mathrm{src}=\mathrm{k} \& \mathrm{id}=218052$

Krishnan, S. G. . \& W. J. R. (2013). A study on impact of employee communication on employee engagement level international research . Journal of Business and Management, 6, 10-15.

Marsen, S. (2020). Navigating Crisis: The Role of Communication in Organizational Crisis. International Journal of Business Communication, 57(2), 162-175.

Men L. R. and Yue, C. A. (2019). Creating a positive emotional culture: Effect of internal communication and impact on employee supportive behaviors. Public Relations Review, 45(3), undefined.

Men, L. R., \& Stacks, D. (2014). The Effects of Authentic Leadership on Strategic Internal Communication and EmployeeOrganization Relationships. Journal of Public Relations Research. https://doi.org/10.1080/1062726X.2014. 908720

Nugroho, F. A.; Kartikawangi, D. (2016). The Airline Crisis Communication: A Text Analysis of AirAsia's Press release Related To The Plane Crash From December 28, 2014 - March 4. InterAct. Journal on Communication, 5(2). https://doi.org/http://dx.doi.org/10.3638 8\%2Fia.v5i2

Schaufeli, W. B., Bakker, A. B., \& Salanova, M. (2006). The Measurement of Work Engagement With a Short Questionnaire. Educational and Psychological Measurement, 66(4). https://doi.org/10.1177/0013164405282 471

Tongam, Hans C.D. ; Kartikawangi, D. (2018). Analisis Teks Strategi Komunikasi Pasca Krisis Mortification dan Follow-up dalam Public Relations Advertising (Kajian pada Teks Video PT. Blue Bird TBK: "Blue Bird Berbenah untuk Berubah" dan "Blue Bird Berubah Menjadi Lebih Baik"). Retrieved from https://lib.atmajaya.ac.id/default.aspx?ta $\mathrm{bID}=61 \& \mathrm{src}=\mathrm{k} \& \mathrm{id}=221463$

Welch, M., \& Jackson, P. R. (2007). Rethinking internal communication: a stakeholder approach. Corporate Communications: An International Journal, 12(2). https://doi.org/10.1108/1356328071074 4847 